\title{
Associations of Serum Nitric Oxide with Vitamin D and Other Metabolic Factors in Apparently Healthy Adolescents
}

\author{
Nasser M. Al-Daghri ${ }^{D}$, Ihtisham Bukhari, Sobhy M. Yakout $(\mathbb{D}$, Shaun Sabico, \\ Malak N. K. Khattak, Ibrahim Aziz, and Majed S. Alokail
}

Prince Mutaib Chair for Biomarkers of Osteoporosis and Biomarkers Research Program, Biochemistry Department, College of Science, King Saud University, Riyadh 11451, Saudi Arabia

Correspondence should be addressed to Nasser M. Al-Daghri; aldaghri2011@gmail.com

Received 7 May 2018; Accepted 26 July 2018; Published 5 August 2018

Academic Editor: Joseph G. Guillemette

Copyright (C) 2018 Nasser M. Al-Daghri et al. This is an open access article distributed under the Creative Commons Attribution License, which permits unrestricted use, distribution, and reproduction in any medium, provided the original work is properly cited.

\begin{abstract}
Introduction. Nitric oxide (NOx) is an important biomolecule which interacts with other molecules including $25(\mathrm{OH}) \mathrm{D}$ to mediate various metabolic pathways. Interactions and associations of $\mathrm{NOx}$ with $25(\mathrm{OH}) \mathrm{D}$ have been well studied both in vitro and in vivo, yet associations in apparently healthy adolescents have never been studied. Methods. A total of 740 (245 boys and 495 girls) apparently healthy Saudi adolescents aged 10-17 years were included in this cross-sectional study, to determine the associations of NOx with 25(OH)D and other biomarkers in Saudi adolescents. Serum NOx, 25(OH)D, and other biochemical and anthropometric parameters were measured following standard protocols and manufacturers' guidelines. Results. NOx level was significantly higher in boys than girls $(p<0.001)$. In all subjects, NOx showed a significant inverse correlation with $25(\mathrm{OH}) \mathrm{D}$. After stratification according to sex however this significant association was observed only in boys and not in girls. NOx was also significantly associated with BMI, serum triglycerides, and systolic blood pressure in all subjects. Conclusion. The significantly inverse association of NOx and 25(OH)D among apparently healthy adolescents is influenced by sex and further strengthens the extraskeletal role of $25(\mathrm{OH}) \mathrm{D}$ in maintaining endothelial homeostasis in this age group, particularly in boys. Whether vitamin D correction can influence NOx production over time among adolescents remains to be proven.
\end{abstract}

\section{Introduction}

Nitric oxide (NOx) is an important molecule produced by endothelium which plays a variety of vital roles in humans such as reproduction, inflammation, vasodilation, cardiac function, oxidative stress, gene transcription, translation, and posttranslational modifications of the proteins [1-6]. Exercise and mental stress reduce bioactivity of NOx which leads to constriction of coronary arteries. Reduced NOx level also facilitates vascular inflammation which may cause oxidation of lipoproteins and foam cell formation, the precursor of atherosclerotic plaque [7]. The disturbance of its endothelial function may lead to hypercholesterolemia, systemic hypertension, diabetes, congestive heart failure, atherosclerosis, pulmonary hypertension, estrogen deficiency, hyperhomocysteinemia, and aging [8]. NOx is synthesized from Larginine, nitric oxide synthase's (NOS) activity which requires calcium/calmodulin $[9,10]$. Calcium-calmodulin complex is formed by the binding of calcium to calmodulin that further binds with the latch domain. The transfer of electron from NADPH via flavin is facilitated by this group which further converts L-arginine and $\mathrm{O} 2$ to L-citrulline and $\mathrm{NOx}$ $[11,12]$. Vitamin D responds to NOS gene which suggests that both molecules have functional association [13]. The active vitamin $\mathrm{D}$ (1,25-dihydroxyvitamin $\mathrm{D}[1,25(\mathrm{OH}) 2 \mathrm{D}]$ ) [14] regulates the production of NOx and/or expression of inducible NOS (iNOS) in different cells including endothelial cells, osteoblasts, microglial cells, macrophages, and astrocytes $[13,15]$. Associations of NOx with vitamin D and its pathogenicity have been well studied in cell lines and animal models $[13,15,16]$. It has also been measured in some chronic diseases but mostly in adults. To the best of our knowledge, no similar report is found in apparently healthy adolescents. Given the importance of NOx and the extra-skeletal effects 
of vitamin $\mathrm{D}$ in the biological system, the present study was conducted to investigate the associations of NOx with $25(\mathrm{OH}) \mathrm{D}$ and various cardiometabolic factors in apparently healthy adolescents of Saudi Arabia.

\section{Materials and Methods}

2.1. Subjects. A total of 740 (245 boys and 495 girls) Saudi adolescents (10-17 years) were included in this cross-sectional study. Subjects' information regarding vitamin D was taken from the school project master database of the Prince Mutaib Chair for the Biomarkers of Osteoporosis (PMCO) in King Saud University (KSU) $[17,18]$. In brief, all subjects were recruited from the different primary schools in Riyadh, Saudi Arabia. Physical examination of the individuals was done to ensure the inclusion criteria; the individuals with serious clinical conditions like chronic kidney or liver diseases, cardiovascular diseases, neurological problems, bone problem, and drugs abusers were excluded from the study. Individuals taking/taken vitamin $\mathrm{D}$ supplementation and those taking treatment for other severe illness were also excluded from study. Anthropometric data was also recorded including height (rounded off to the nearest $0.5 \mathrm{~cm}$ ), weight (rounded off to the nearest $0.1 \mathrm{~kg}$ ), waist and hip circumference (centimeters), and mean systolic and diastolic blood pressure (millimeters of $\mathrm{Hg}$ ). Body mass index (BMI) was calculated as weight $(\mathrm{kg})$ divided by height in square meters and individuals with $\mathrm{BMI} \geq 25 \mathrm{~kg} / \mathrm{m}^{2}$ and $\geq 30 \mathrm{~kg} / \mathrm{m}^{2}$ were considered overweight and obese, respectively. We excluded subjects who were underweight, overweight, and obese, based on their BMI z-scores. We recruited only apparently normal individuals for current study.

2.2. Sample Collection. A total 5-10 CC fasting venous blood samples were collected from all subjects. Part of the blood samples were centrifuged for serum isolation while remaining blood samples were transferred to EDTA tubes for other future analyses. Blood and serum samples were immediately delivered and stored at $-80^{\circ} \mathrm{C}$ in PMCO, KSU, Riyadh, KSA.

2.3. Biochemical Analyses. Fasting lipid profile and blood glucose in all recruited individuals were determined using a chemical analyzer (Konelab 20XTi, Thermo Electron Corporation, Vantaa, Finland). COBAS e-411 automated analyzer (Roche Diagnostics, Indianapolis, IN, USA) was used for measuring serum $25(\mathrm{OH}) \mathrm{D}$. The inter- and intra-assay were applied for estimation of serum $25(\mathrm{OH}) \mathrm{D}$; coefficients of variation $(\mathrm{CV})$ were taken as 8.0 and $5.6 \%$, respectively, with a lower detection limit (LOD) of $7.5 \mathrm{nmol} / \mathrm{ml}$ [19].

Usually, NOx can be estimated from determining the concentrations of nitrite and nitrate end products. The measurement of nitrate/nitrite concentration or of total nitrate and nitrite concentration is routinely used as an index of NOx production [15]. The concentration of serum NOx was measured using the Griess reaction [20]. Because of its simplicity, it has been used extensively in analysis of numerous biological samples including plasma (serum), urine, CSF, saliva, and cell culture media. In this method, nitrite is first treated with a diazotizing reagent, e.g., sulfanilamide (SA), in acidic media to form a transient diazonium salt. This intermediate is then allowed to react with a coupling reagent, $\mathrm{N}$-naphthyl-ethylenediamine (NED), to form a stable azo compound that can be measured spectrophotometry. In brief, $50 \mu \mathrm{L}$ serum samples and $50 \mu \mathrm{L}$ of distilled water (blank) were added to microplate wells, and $50 \mu \mathrm{L}$ sulfanilamide $(1 \%$ in $5 \% \mathrm{H} 3 \mathrm{PO} 4)$ was added to samples. Samples were incubated for $10 \mathrm{~min}$ at $37^{\circ} \mathrm{C}$. $50 \mu \mathrm{L}$ of [N-(1-naphthyl) ethylendiamine dihydrochloride $(0.1 \%)$ in distilled water] was then added to both samples and blank and reincubated for $5 \mathrm{~min}$ at $37^{\circ} \mathrm{C}$. Absorbance was taken at $540 \mathrm{~nm}$ using the enzymelinked immunosorbent assay (ELISA) reader (Sunrise, Tecan, Austria). Serum NOx concentration was determined from the linear standard curve established using $0-50 \mu \mathrm{M}$ sodium nitrate. Inter- and intra-assay coefficients of variations were set at $5.2 \%$ and $4.4 \%$, respectively, while the recovery of the assay was $93 \pm 1.5 \%$.

2.4. Statistical Analysis. SPSS (version 21.0, IBM) was used to analyze the data. Continuous data were presented as mean \pm standard deviation (SD) for normal variables and non-Gaussian variables were presented in median (1st and 3rd) percentiles. Categorical data were presented as frequencies and percentages (\%). All continuous variables were checked for normality using Kolmogorov-Smirnov test. NonGaussian variables were log-transformed prior to parametric analysis. Correlations between variables were done using Pearson's correlation analysis. Independent T-test was used to compare mean differences. A $p$ value $<0.05$ was considered statistically significant.

\section{Results}

A total of 740 (245 boys and 495 girls) were recruited to analyze the biological relation of NOx with vitamin D and other serological parameters. Initially, the general characteristics of subjects were studied and no significant differences were found between the mean age and triglycerides. Significantly higher BMI and hip circumference were noted in boys $(p<0.001)$ while girls had significantly higher WHR and waist circumference $(p<0.001)$. Girls also had significantly higher systolic blood pressure while boys had significantly higher diastolic blood pressure. Girls showed significantly higher levels of serum total cholesterol and 25(OH)D while the boys had significantly higher levels of triglycerides and NOx $(p<0.001)$ (Table 1$)$. The sexually dimorphic associations between vitamin D and NOx levels are shown in Figure 1. Furthermore, the bivariate associations of $\mathrm{NOx}$ were studied with other parameters like age, blood pressure, total cholesterol, and triglycerides. The mean age, systolic blood pressure, and triglycerides had positive correlation while total cholesterol and HDL-cholesterol showed inverse correlation with NOx. The NOx in girls showed a significant positive correlation between hip circumference, systolic blood pressure, and triglycerides while inverse correlations were found between cholesterol, HDL, and serum 25(OH)D. In all subjects, NOx did not show an association with BMI, waist, WHR, and diastolic blood pressure and glucose 
TABLE 1: Clinical characteristics of the subjects.

\begin{tabular}{|c|c|c|c|c|}
\hline Parameter & All & Boys & Girls & P-Value \\
\hline $\mathbf{N}$ & 740 & $245(33.1)$ & $495(66.9)$ & \\
\hline Age (years) & $14.2 \pm 1.6$ & $14.1 \pm 1.2$ & $14.3 \pm 1.8$ & 0.18 \\
\hline Body Mass Index $\left(\mathrm{kg} / \mathrm{m}^{2}\right)$ & $21.9 \pm 4.8$ & $22.7 \pm 4.4$ & $21.5 \pm 4.9$ & 0.003 \\
\hline Waist circumference $(\mathrm{cm})$ & $73.6 \pm 11.7$ & $72.2 \pm 10.0$ & $74.7 \pm 12.8$ & 0.011 \\
\hline Hip circumference $(\mathrm{cm})$ & $88.0 \pm 11.2$ & $92.8 \pm 10.1$ & $84.3 \pm 10.6$ & $<0.001$ \\
\hline WHR & $0.8 \pm 0.09$ & $0.8 \pm 0.1$ & $0.9 \pm 0.1$ & $<0.001$ \\
\hline Systolic BP (mmHg) & $119.4 \pm 14.0$ & $116.0 \pm 13.0$ & $121.0 \pm 14.2$ & $<0.001$ \\
\hline Diastolic BP (mmHg) & $70.1 \pm 9.8$ & $72.6 \pm 10.2$ & $68.9 \pm 9.3$ & $<0.001$ \\
\hline Glucose $(\mathrm{mmol} / \mathrm{l})$ & $5.1 \pm 0.7$ & $4.9 \pm 0.8$ & $5.2 \pm 0.7$ & $<0.001$ \\
\hline Triglycerides (mmol/l)\# & $1.0(0.8-1.4)$ & $1.0(0.8-1.4)$ & $1.0(0.8-1.4)$ & 0.62 \\
\hline Total Cholesterol (mmol/l) & $4.3 \pm 1.0$ & $4.0 \pm 1.1$ & $4.4 \pm 0.9$ & $<0.001$ \\
\hline HDL-Cholesterol (mmol/l) & $1.2 \pm 0.4$ & $1.0 \pm 0.2$ & $1.3 \pm 0.4$ & $<0.001$ \\
\hline LDL-Cholesterol (mmol/l) & $2.6 \pm 0.8$ & $2.6 \pm 0.8$ & $2.6 \pm 0.8$ & 0.310 \\
\hline LDL/HDL ratio & $2.5 \pm 1.2$ & $2.7 \pm 0.9$ & $2.4 \pm 1.3$ & 0.004 \\
\hline 25(OH)D (nmol/l)\# & $33.6(24.9-46.6)$ & $25.6(20.2-32.2)$ & $38.6(29.7-50.2)$ & $<0.001$ \\
\hline Nitric Oxide $(\mu \mathrm{mol} / \mathrm{l}) \#$ & $12.8(5.7-26.4)$ & $21.9(12.8-37.5)$ & $9.3(5.0-20.0)$ & $<0.001$ \\
\hline
\end{tabular}

Note: data is presented as N (\%) for frequencies and mean \pm standard deviation for normal continuous variables; \# denotes non-Gaussian variables presented as median $\left(25^{\text {th }}-75^{\text {th }}\right)$ percentiles; P-value is significant at 0.05 .

(Table 2). The differences of vitamin $\mathrm{D}$ status in subjects were measured according to the values analyzed previously [21] as sufficient, deficient, and insufficient $(75 \mathrm{nmol} / \mathrm{L},>50$ and $<75 \mathrm{nmol} / \mathrm{L}$, and $<50 \mathrm{nmol} / \mathrm{L}$ ), respectively. There were no significant differences between mean glucose, systolic blood pressure, HDL/ LDL, LDL/HDL ratio, and triglycerides in all groups. Significantly higher BMI, hip circumference, diastolic blood pressure, and NOx were observed in vitamin $\mathrm{D}$ deficient group ( $p$ value $<0.001)$, whereas the vitamin D sufficient group had significantly higher mean values of WHR, total cholesterol, and vitamin D (Table 3). Vitamin $\mathrm{D}$ insufficient group showed a significant positive correlation with hip circumference, systolic blood pressure, and triglycerides. Triglycerides also showed a positive association with deficient and sufficient group while LDL/HDL ratio was found only in the deficient group. Inverse associations with total and HDL- and LDL-cholesterol were found and WHR was inversely associated with NOx in the insufficient group (Table 4). For confirmation, based on the vitamin D status $(75 \mathrm{nmol} / \mathrm{L},>50$ and $<75 \mathrm{nmol} / \mathrm{L}$, and $<50 \mathrm{nmol} / \mathrm{L})$ all individuals were grouped into three categories (sufficient, deficient, and insufficient), respectively. It was found that individuals having low vitamin D levels (insufficient group) had higher levels of NOx (Figure 2).

\section{Discussion}

Vitamin D and NOx are important molecules that may have a functional association as observed in different cell lines, animal models, and humans. Different studies showed different associations, so this ambiguity has been a hot topic that remains unanswered. NOx has a role in the pathogenicity of several illnesses like neurodegenerative diseases (e.g., excitotoxicity following stroke, multiple sclerosis, Alzheimer's,

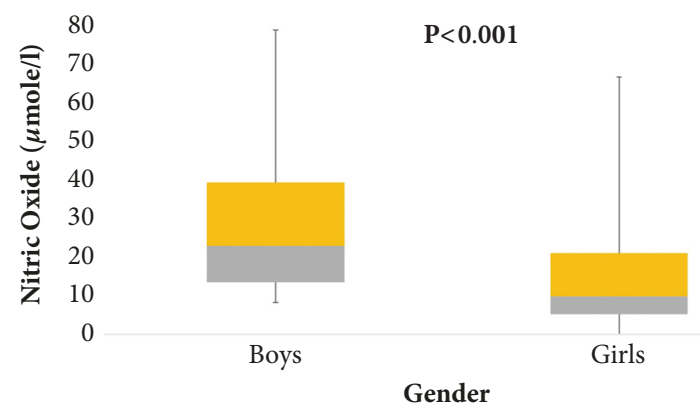

FIGURE 1: Data is presented in median $\left(1^{\text {st }}-3^{\text {rd }}\right)$ percentiles. $* * *$ represents overall significance at 0.01 level.

and Parkinson's diseases asthma), CVD, arthritis, and infertility $[6,22-25]$. NOx also has a protective role against osteoarthritis [26].

It has been observed that $1,25(\mathrm{OH}) 2 \mathrm{D} 3$ reduces PFFinduced NOx response in primary human osteoblasts while 25(OH)D3 did not show significant effects on NOx response in primary human osteoblasts [16]. Without the action of mechanical stimuli like vitamin D receptor, $1,25(\mathrm{OH})(2) \mathrm{D}(3)$ improves the production of NOx and expression of inducibleNOS osteoblasts [13]. The addition of 25(OH)D to HD11 cells and monocytes in the presence of lipopolysaccharide (LPS) increases nitrate production 3-5-fold approximately. Consistent increase in nitrate production was reported in HD11 cells with the consistent increase in doses of 25(OH)D [27]. It has also been noted that addition of vitamin $\mathrm{D}$ increases production of endothelial NOx [15]. By adding vitamin D to the diet of atherosclerotic rabbits, a significant increase was noted in NOx production. Hence, authors concluded that vitamin $\mathrm{D}$ has antiatherosclerotic effects and stimulate NOx 
TABLE 2: Association between NOx and other parameters.

\begin{tabular}{lccc}
\hline Parameters & All & Boys & Girls \\
\hline $\mathrm{N}(\%)$ & 740 & $245(33.1)$ & $495(66.9)$ \\
\hline Age $($ years $)$ & 0.01 & $0.25 * *$ & 0.06 \\
\hline Body Mass Index $\left(\mathrm{kg} / \mathrm{m}^{2}\right)$ & $0.10 *$ & 0.07 & 0.04 \\
\hline Waist circumference $(\mathrm{cm})$ & $0.09 *$ & 0.03 & 0.10 \\
\hline Hip circumference $(\mathrm{cm})$ & $0.20 * *$ & 0.03 & $0.12 *$ \\
\hline WHR & $-0.12 * *$ & -0.04 & 0.04 \\
\hline Systolic Blood Pressure $(\mathrm{mmHg})$ & $0.11 * *$ & $0.33 * *$ & $-0.13 * *$ \\
\hline Diastolic Blood Pressure $(\mathrm{mmHg})$ & $0.10 *$ & -0.04 & 0.08 \\
\hline Glucose $(\mathrm{mmol} / \mathrm{l})$ & -0.06 & -0.03 & 0.03 \\
\hline Triglycerides $(\mathrm{mmol} / \mathrm{l}) \#$ & $0.26 * *$ & $0.25 * *$ \\
\hline Total Cholesterol $(\mathrm{mmol} / \mathrm{l})$ & $-0.36 * *$ & $-0.38 * *$ \\
\hline LDL-Cholesterol $(\mathrm{mmol} / \mathrm{l})$ & $-0.22 * *$ & -0.11 & $-0.31 * *$ \\
\hline LDL/HDL ratio & 0.07 & $0.15 *$ & $-0.29 * *$ \\
\hline HDL-Cholesterol $(\mathrm{mmol} / \mathrm{l})$ & $-0.38 * *$ & $-0.38 * *$ \\
\hline 25(OH)D $(\mathrm{nmol} / \mathrm{l}) \#$ & $-0.21 * *$ & 0.04 & -0.01 \\
\hline
\end{tabular}

Note: data is presented as coefficient (R); \# denotes log transform; * denotes significance at 0.05 level; $* *$ denotes significance at 0.01 level.

TABle 3: Clinical characteristics of the subject.

\begin{tabular}{|c|c|c|c|c|}
\hline Parameter & Deficient & Insufficient & Sufficient & P-Value \\
\hline $\mathrm{N}(\%)$ & $186(25.1)$ & $418(56.5)$ & $136(18.4)$ & P-varute \\
\hline Age (years) & $14.5 \pm 1.5$ & $14.2 \pm 1.5$ & $13.4 \pm 1.8^{* !}$ & $<0.001$ \\
\hline Body Mass Index $\left(\mathrm{kg} / \mathrm{m}^{2}\right)$ & $22.7 \pm 4.8$ & $22.0 \pm 4.7$ & $19.9 \pm 3.9^{* !}$ & $<0.001$ \\
\hline Waist circumference $(\mathrm{cm})$ & $73.0 \pm 10.8$ & $74.3 \pm 11.7$ & $70.0 \pm 12.1^{!}$ & 0.010 \\
\hline Hip circumference $(\mathrm{cm})$ & $91.0 \pm 10.8$ & $87.5 \pm 9.7^{*}$ & $80.5 \pm 11.3^{* !}$ & $<0.001$ \\
\hline WHR & $0.8 \pm 0.1$ & $0.8 \pm 0.1$ & $0.9 \pm 0.1$ & $<0.001$ \\
\hline Systolic BP (mmHg) & $119.1 \pm 14.5$ & $119.9 \pm 13.2$ & $117.2 \pm 15.4$ & 0.23 \\
\hline Diastolic BP (mmHg) & $72.2 \pm 10.1$ & $69.9 \pm 9.4^{*}$ & $68.2 \pm 9.6^{* !}$ & 0.005 \\
\hline Glucose $(\mathrm{mmol} / \mathrm{l})$ & $5.1 \pm 0.8$ & $5.2 \pm 0.7$ & $5.0 \pm 0.6$ & 0.12 \\
\hline Triglycerides (mmol/l)\# & $1.1(0.8-1.5)$ & $1.0(0.8-1.3)$ & $1.0(0.8-1.3)$ & 0.13 \\
\hline Total Cholesterol $(\mathrm{mmol} / \mathrm{l})$ & $4.1 \pm 1.1$ & $4.3 \pm 1.0$ & $4.5 \pm 1.0^{*}$ & 0.015 \\
\hline HDL-Cholesterol (mmol/l) & $1.2 \pm 0.4$ & $1.2 \pm 0.4$ & $1.2 \pm 0.4$ & 0.42 \\
\hline LDL-Cholesterol (mmol/l) & $2.5 \pm 0.7$ & $2.6 \pm 0.8$ & $2.7 \pm 0.9$ & 0.22 \\
\hline LDL/HDL ratio & $2.4 \pm 0.9$ & $2.4 \pm 1.2$ & $2.6 \pm 1.5$ & 0.17 \\
\hline $25(\mathrm{OH}) \mathrm{D}(\mathrm{nmol} / \mathrm{l}) \#$ & $20.4(18.3-22.5)$ & $35.1(30.0-49.5)^{*}$ & $59.8(53.2-65.5)^{* !}$ & $<0.001$ \\
\hline Nitric Oxide $(\mu$ mole/l)\# & $18.0(8.9-33.5)$ & $12.9(5.2-25.4)^{*}$ & $7.4(4.4-12.7)^{* !}$ & $<0.001$ \\
\hline
\end{tabular}

Note: data is presented as $\mathrm{N}(\%)$ for frequencies and mean \pm standard deviation for normal continuous variables; \# denotes continuous variables with nonGaussian distribution presented as median $\left(25^{\text {th }}-75^{\text {th }}\right)$ percentiles; P-value is significant at 0.05 and 0.01 . “*” denotes significance compared to deficient; "!" denotes significance compared to insufficient.

production which attenuates the inflammatory atherosclerotic process [28]. A significant direct relationship was noted between NOx and vitamin D in African-American men [29]. On the other hand, contradictory results were shown in various studies; the functional relation of vitamin $\mathrm{D}$ and exhaled NOx in lungs was studied in children (ages $=5$ 18) but no significant association was found. Similarly, no association was shown between $25(\mathrm{OH}) \mathrm{D}$ and exhaled $\mathrm{NOx}$ in children with asthma [30]. Vitamin D reduces asthma by restricting NOx production and expression of iNOS in lungs [31]. Similar results were found in cell line RAW 264.7 in which increasing doses of $1,25(\mathrm{OH})(2) \mathrm{D}(3)$ inhibited iNOS messenger RNA expression and the production of NOx was also reduced with increasing vitamin D. Even no association was found between vitamin D binding protein (DBP) and NOx production by mononuclear cells [32]. The negative correlation was found between the NOx production and level of $1,25(\mathrm{OH})(2) \mathrm{D}(3)$ in peripheral-blood mononuclear cells (PBMCs) taken from hypercalcemia and tuberculosis patients [33]. Similarly, current findings showed an inverse association between vitamin D and NOx. While NOx has shown positive associations between high systolic blood 
TABle 4: Association between nitric oxide with other parameters according to vitamin D status.

\begin{tabular}{lccc}
\hline Parameter & Deficient & Insufficient & Sufficient \\
\hline $\mathrm{N}$ & $186(25.1)$ & $418(56.5)$ & $136(18.4)$ \\
\hline Age (years) & 0.03 & -0.003 & 0.08 \\
\hline Body Mass Index $\left(\mathrm{kg} / \mathrm{m}^{2}\right)$ & -0.01 & 0.06 & 0.04 \\
\hline Waist circumference $(\mathrm{cm})$ & 0.05 & -0.04 & 0.10 \\
\hline Hip circumference $(\mathrm{cm})$ & 0.05 & $0.17 * *$ & 0.05 \\
\hline WHR & -0.003 & $-0.26 * *$ & 0.14 \\
\hline Systolic BP $(\mathrm{mmHg})$ & 0.11 & $0.11 * *$ & 0.08 \\
\hline Diastolic BP $(\mathrm{mmHg})$ & 0.13 & 0.10 & -0.12 \\
\hline Glucose $(\mathrm{mmol} / \mathrm{l})$ & -0.03 & -0.08 & -0.05 \\
\hline Triglycerides $(\mathrm{mmol} / \mathrm{l}) \#$ & $0.20 *$ & $0.32 * *$ & $0.24 *$ \\
\hline Total Cholesterol $(\mathrm{mmol} / \mathrm{l})$ & $-0.36 * *$ & $-0.34 * *$ \\
\hline HDL-Cholesterol $(\mathrm{mmol} / \mathrm{l})$ & $-0.39 * *$ & $-0.41 * *$ & $-0.26 * *$ \\
\hline LDL-Cholesterol $(\mathrm{mmol} / \mathrm{l})$ & $-0.19 *$ & $-0.18 * *$ & $-0.22 * *$ \\
\hline LDL/HDL ratio & $0.21 *$ & 0.11 & $-0.29 * *$ \\
\hline 25(OH)D (nmol/l)\# & 0.06 & -0.04 & -0.09 \\
\hline
\end{tabular}

Note: data is presented as coefficient (R); \# denotes log transform; * denotes significance at 0.05 level; $* *$ denotes significance at 0.01 level.

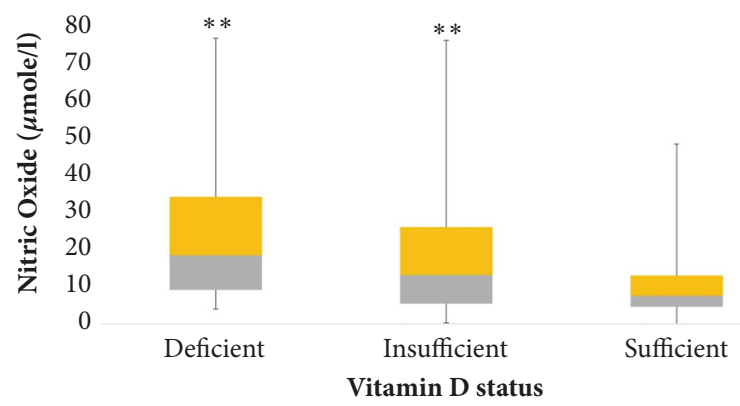

FIGURE 2: Data is presented in median $\left(1^{\text {st }}-3^{\text {rd }}\right)$ percentiles. $* * *$ represents overall significance at 0.01 level; $* *$ represents significance between deficient and insufficient ones at 0.01 level.

pressure and triglycerides in the girls group, no associations were found with total cholesterol, HDL, and vitamin D. Inverse association has been shown in NOx and systolic blood pressure among patients with myocardial infraction [34]. In pregnant women with hypertension, NOx synthesis was significantly reduced with increased levels of triglycerides and cholesterol [35]. Current individuals having high/low level of NOx and vitamin D were apparently normal adolescents, without any sign of bone or other serious diseases previously associated with NOx or vitamin D production. The associations between NOx, high systolic blood pressure, and triglycerides have not been studied previously in healthy adolescents.

Although our findings are similar to previous studies and the relatively large sample size had sufficient statistical power to explain the relationship between $\mathrm{NOx}$ and other parameters, the study still has some limitations. One is its cross-sectional design, which precludes our ability to make causal inferences about the observed associations. We also did not measure levels of lactate and other inflammatory markers which may give additional insights into the significant associations elicited. These markers can be recommended for further investigations. Furthermore since our subjects were adolescents, we did not study the involvement of growth hormones and sex steroids, which are suggested to have influence on NOx and 25(OH)D levels. Finally, since the associations observed do not prove causality, a sufficient vitamin D status may, at best, serve as a "marker" for other conditions, e.g., for good health or for UV exposure. In consequence, it can be speculated whether the associations observed may be caused by other, unknown factors that are associated, e.g., with good health or UV exposure.

In summary, the associations of NOx with $25(\mathrm{OH}) \mathrm{D}$ and other cardiometabolic parameters were studied in 740 Saudi adolescents. Serum 25(OH)D and NOx showed a significant inverse association in all subjects, more so in boys, and NOx was positively associated with triglycerides and systolic blood pressure. The association between the NOx and the parameters measured are significantly influenced by sex and age. A large scale study on people of different ages and ethnicity would help in better understanding of the NOx's association pattern with metabolic and clinical factors.

\section{Abbreviations \\ NO: $\quad$ Nitric oxide \\ 25(OH)D: 25-Hydroxyvitamin D \\ CVD: $\quad$ Cardiovascular diseases \\ HDL: High quality lipoproteins \\ LDL: $\quad$ Low quality lipoproteins \\ WHR: Waist hip ratio \\ BMI: $\quad$ Body mass index.}

\section{Data Availability}

The data used to support the findings of this study are available from the corresponding author upon request. 


\section{Ethical Approval}

All the experimental and sampling procedures were approved by ethical review board of the College of Science, KSU, Riyadh, Kingdom of Saudi Arabia. All procedures were performed in accordance with the ethical standards of the Helsinki Declaration of 1964 and its latest amendments.

\section{Consent}

A detailed project description was shared with all individuals and their parents/guardians, and written informed consent was obtained from parents/guardian and each of recruited individuals. All participants were asked to complete the predesigned questionnaire about their general health and past medical history.

\section{Conflicts of Interest}

The authors declare that they have no conflicts of interest.

\section{Authors' Contributions}

Nasser M. Al-Daghri, Majed S. Alokail, and Sobhy M. Yakout conceived and designed the experiments. Ihtisham Bukhari, Ibrahim Aziz, Malak N. K. Khattak, and Shaun Sabico analyzed the data. Ihtisham Bukhari and Shaun Sabico wrote the paper. Modification of the manuscript was carried out by Ihtisham Bukhari, Sobhy M. Yakout, Shaun Sabico, and Nasser M. Al-Daghri. All authors have read and approved the final version of the manuscript for publication.

\section{Acknowledgments}

The authors highly acknowledge the participation of the individuals in their study and they are also highly grateful to the Prince Mutaib Chair for Biomarkers of Osteoporosis, Biochemistry Department, College of Science, King Saud University, and Deanship of Scientific Research for the technical support. The study was funded by Prince Mutaib Chair for Biomarkers of Osteoporosis and Deanship of Scientific Research, King Saud University, Riyadh, KSA.

\section{References}

[1] B. V. Khan, D. G. Harrison, M. T. Olbrych, R. W. Alexander, and R. M. Medford, "Nitric oxide regulates vascular cell adhesion molecule 1 gene expression and redox-sensitive transcriptional events in human vascular endothelial cells," Proceedings of the National Acadamy of Sciences of the United States of America, vol. 93, no. 17, pp. 9114-9119, 1996.

[2] T. Gudi, G. K.-P. Hong, A. B. Vaandrager, S. M. Lohmann, and R. B. Pilz, "Nitric oxide and cGMP regulate gene expression in neuronal and glial cells by activating type II cGMP-dependent protein kinase," The FASEB Journal, vol. 13, no. 15, pp. 2143-2152, 1999.

[3] K. Pantopoulos and M. W. Hentze, "Nitric oxide signaling to iron-regulatory protein: Direct control of ferritin mRNA translation and transferrin receptor mRNA stability in transfected fibroblasts," Proceedings of the National Acadamy of Sciences of the United States of America, vol. 92, no. 5, pp. 1267-1271, 1995.

[4] X.-B. Liu, P. Hill, and D. J. Haile, "Role of the ferroportin ironresponsive element in iron and nitric oxide dependent gene regulation," Blood Cells, Molecules \& Diseases, vol. 29, no. 3, pp. 315-326, 2002.

[5] B. Brüne, S. Dimmeler, L. M. y Vedia, and E. G. Lapetina, "Nitric oxide: A signal for ADP-ribosylation of proteins," Life Sciences, vol. 54, no. 2, pp. 61-70, 1994.

[6] M. Rosselli, P. J. Keller, and R. K. Dubey, "Role of nitric oxide in the biology, physiology and pathophysiology of reproduction," Human Reproduction Update, vol. 4, no. 1, pp. 3-24, 1998.

[7] R. O. Cannon III, "Role of nitric oxide in cardiovascular disease: focus on the endothelium," Clinical Chemistry, vol. 44, no. 8, part 2, pp. 1809-1819, 1998.

[8] T. M. Dawson and S. H. Snyder, "Gases as biological messengers: Nitric oxide and carbon monoxide in the brain," The Journal of Neuroscience, vol. 14, no. 9, pp. 5147-5159, 1994.

[9] C. R. Lyons, G. J. Orloff, and J. M. Cunningham, "Molecular cloning and functional expression of an inducible nitric oxide synthase from a murine macrophage cell line," The Journal of Biological Chemistry, vol. 267, no. 9, pp. 6370-6374, 1992.

[10] U. Förstermann and W. C. Sessa, "Nitric oxide synthases: regulation and function," European Heart Journal, vol. 33, no. 7, pp. 829-837, 2012.

[11] H. M. Abu-Soud, P. L. Feldman, P. Clark, and D. J. Stuehr, "Electron transfer in the nitric-oxide synthases: characterization of L-arginine analogs that block heme iron reduction," The Journal of Biological Chemistry, vol. 269, no. 51, pp. 32318-32326, 1994.

[12] U. Siddhanta, C. Wu, H. M. Abu-Soud, J. Zhang, D. K. Ghosh, and D. J. Stuehr, "Heme iron reduction and catalysis by a nitric oxide synthase heterodimer containing one reductase and two oxygenase domains," The Journal of Biological Chemistry, vol. 271, no. 13, pp. 7309-7312, 1996.

[13] H. M. E. Willems, E. G. H. M. Van Den Heuvel, G. Carmeliet, A. Schaafsma, J. Klein-Nulend, and A. D. Bakker, "VDR dependent and independent effects of 1,25-dihydroxyvitamin D 3 on nitric oxide production by osteoblasts," Steroids, vol. 77, no. 1-2, pp. 126-131, 2012.

[14] M. F. Holick, "Vitamin D deficiency," The New England Journal of Medicine, vol. 357, no. 3, pp. 266-281, 2007.

[15] C. Molinari, F. Uberti, E. Grossini et al., " $1 \alpha, 25$-dihydroxycholecalciferol induces nitric oxide production in cultured endothelial cells," Cellular Physiology and Biochemistry, vol. 27, no. 6, pp. 661-668, 2011.

[16] K. Van Der Meijden, A. D. Bakker, H. W. Van Essen et al., "Mechanical loading and the synthesis of 1,25(OH)2D in primary human osteoblasts," The Journal of Steroid Biochemistry and Molecular Biology, vol. 156, pp. 32-39, 2016.

[17] N. M. Al-Daghri, N. J. Aljohani, O. S. Al-Attas et al., "Comparisons in childhood obesity and cardiometabolic risk factors among urban Saudi Arab adolescents in 2008 and 2013," Child: Care, Health and Development, vol. 42, no. 5, pp. 652-657, 2016.

[18] N. M. Al-Daghri, Y. Al-Saleh, N. Aljohani et al., "Vitamin D deficiency and cardiometabolic risks: A juxtaposition of arab adolescents and adults," PLOS ONE, vol. 10, no. 7, Article ID 131315, 2015.

[19] D. Sowah, X. Fan, L. Dennett, R. Hagtvedt, and S. Straube, "Vitamin D levels and deficiency with different occupations: A systematic review," BMC Public Health, vol. 17, no. 1, article no. 519, 2017. 
[20] D. Tsikas, "Analysis of nitrite and nitrate in biological fluids by assays based on the Griess reaction: appraisal of the Griess reaction in the l-arginine/nitric oxide area of research," Journal of Chromatography B, vol. 851, no. 1-2, pp. 51-70, 2007.

[21] N. M. Al-Daghri, Y. Al-Saleh, N. Aljohani et al., "Vitamin D status correction in Saudi Arabia: an experts' consensus under the auspices of the European Society for Clinical and Economic Aspects of Osteoporosis, Osteoarthritis, and Musculoskeletal Diseases (ESCEO)," Archives of Osteoporosis, vol. 12, no. 1, article no. 1, 2017.

[22] C. F. H. Mueller, K. Laude, J. S. McNally, and D. G. Harrison, "Redox mechanisms in blood vessels," Arteriosclerosis, Thrombosis, and Vascular Biology, vol. 25, no. 2, pp. 274-278, 2005.

[23] J. R. Steinert, T. Chernova, and I. D. Forsythe, "Nitric oxide signaling in brain function, dysfunction, and dementia," The Neuroscientist, vol. 16, no. 4, pp. 435-452, 2010.

[24] A. J. Farrell, D. R. Blake, R. M. J. Palmer, and S. Moncada, "Increased concentrations of nitrite in synovial fluid and serum samples suggest increased nitric oxide synthesis in rheumatic diseases," Annals of the Rheumatic Diseases, vol. 51, no. 11, pp. 1219-1222, 1992.

[25] Y. Okuda, Y. Nakatsuji, H. Fujimura et al., "Expression of the inducible isoform of nitric oxide synthase in the central nervous system of mice correlates with the severity of actively induced experimental allergic encephalomyelitis," Journal of Neuroimmunology, vol. 62, no. 1, pp. 103-112, 1995.

[26] S. B. Abramson, "Osteoarthritis and nitric oxide," Osteoarthritis and Cartilage, vol. 16, no. 2, pp. S15-S20, 2008.

[27] A. Morris and R. K. Selvaraj, "In vitro 25-hydroxycholecalciferol treatment of lipopolysaccharide-stimulated chicken macrophages increases nitric oxide production and mRNA of interleukinlbeta and 10," Veterinary Immunology and Immunopathology, vol. 161, no. 3-4, pp. 265-270, 2014.

[28] H. A. Malek and A. Shata, "Effect of a high dose of vitamin D on a rabbit model of atherosclerosis," International Journal of Immunopathology and Pharmacology, vol. 27, no. 2, pp. 195-201, 2014.

[29] A. L. Valiña-Tóth, Z. Lai, S. Zhang, and J. M. Flack, "Vitamin $\mathrm{D}$ and parathyroid hormone relationships with urinary nitric oxide metabolites and plasma isoprostanes in africanamericans," Cardiorenal Medicine, vol. 2, no. 3, pp. 234-242, 2012.

[30] W. Checkley, C. L. Robinson, L. M. Baumann et al., "25hydroxy vitamin D levels are associated with childhood asthma in a population-based study in Peru," Clinical \& Experimental Allergy, vol. 45, no. 1, pp. 273-282, 2015.

[31] Y. Zhou, X. Zhou, and X. Wang, "1,25-Dihydroxyvitamin D3 prevented allergic asthma in a rat model by suppressing the expression of inducible nitric oxide synthase," Allergy and Asthma Proceedings, vol. 29, no. 3, pp. 258-267, 2008.

[32] A. J. López-Farré, J. Modrego, L. Azcona et al., "Nitric oxide from mononuclear cells may be involved in platelet responsiveness to aspirin," European Journal of Clinical Investigation, vol. 44, no. 5, pp. 463-469, 2014.

[33] J.-M. Chang, M.-C. Kuo, H.-T. Kuo et al., "1- $\alpha, 25-$ Dihydroxyvitamin D3 regulates inducible nitric oxide synthase messenger RNA expression and nitric oxide release in macrophage-like RAW 264.7 cells," Journal of Laboratory and Clinical Medicine, vol. 143, no. 1, pp. 14-22, 2004.

[34] F. Baraas, L. Rilantono, S. Diniharini, I. Kurniawan, R. Christian, and D. Kusmana, "Effect of short-term low-intensity exercise training on association of oxygen free radicals and nitric oxide production in patients with acute myocardial infarction," International Journal of Angiology, vol. 22, no. 3, pp. 159-164, 2013.

[35] M. Mayret-Mesquiti, O. Pérez-Méndez, M. E. Rodríguez et al., "Hypertriglyceridemia is linked to reduced nitric oxide synthesis in women with hypertensive disorders of pregnancy," Hypertension in Pregnancy, vol. 26, no. 4, pp. 423-431, 2007. 


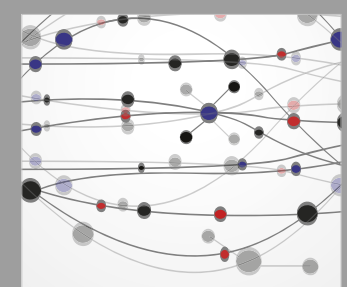

The Scientific World Journal
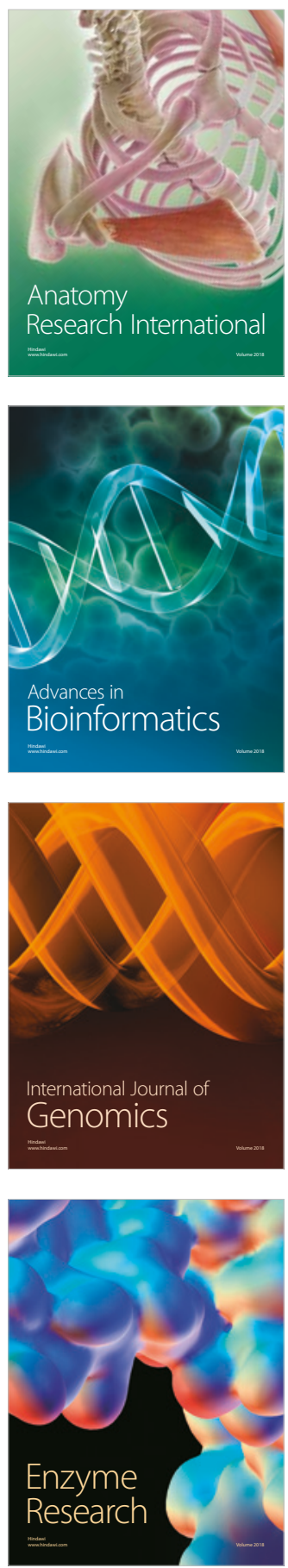
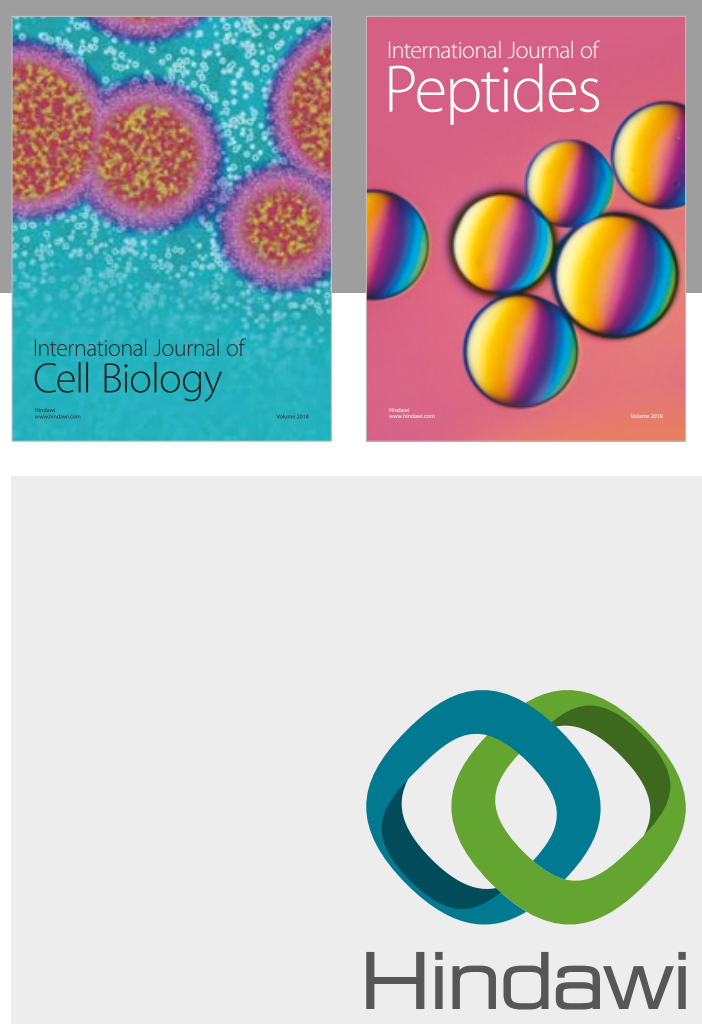

Submit your manuscripts at

www.hindawi.com
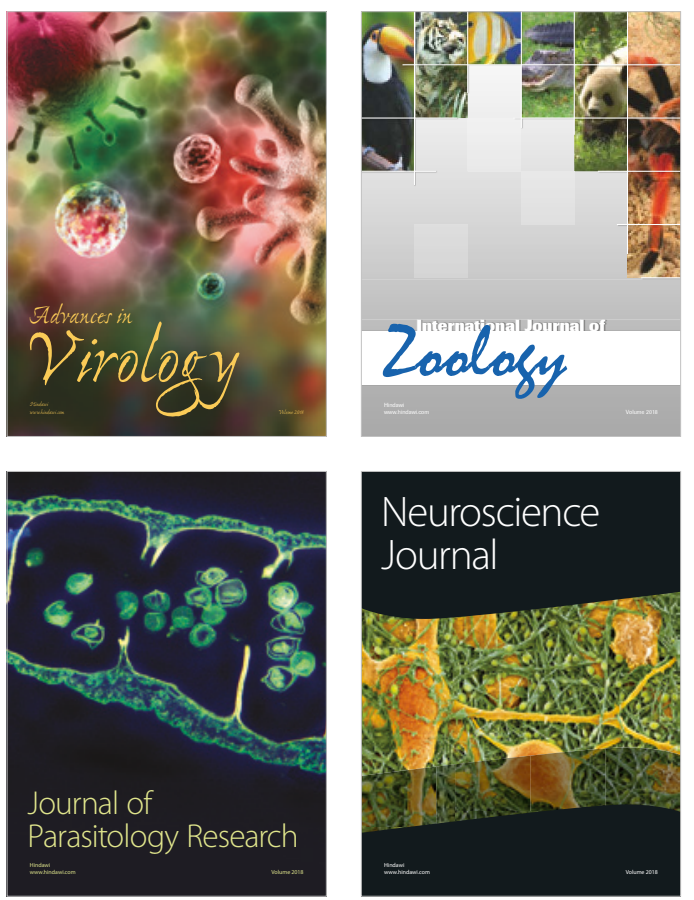
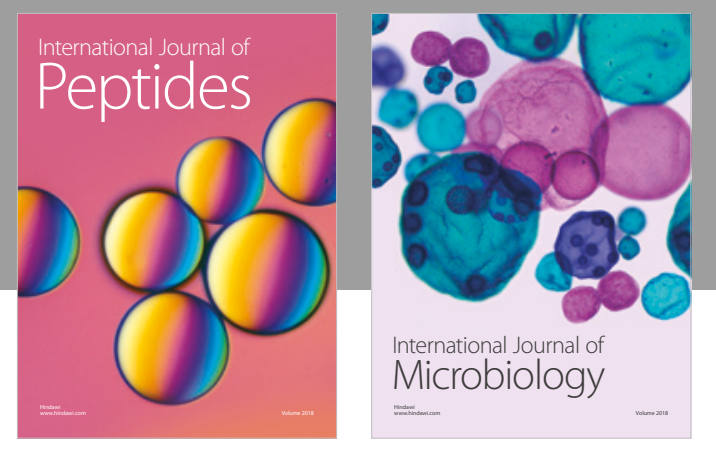

nternational Journal of Microbiology
Journal of
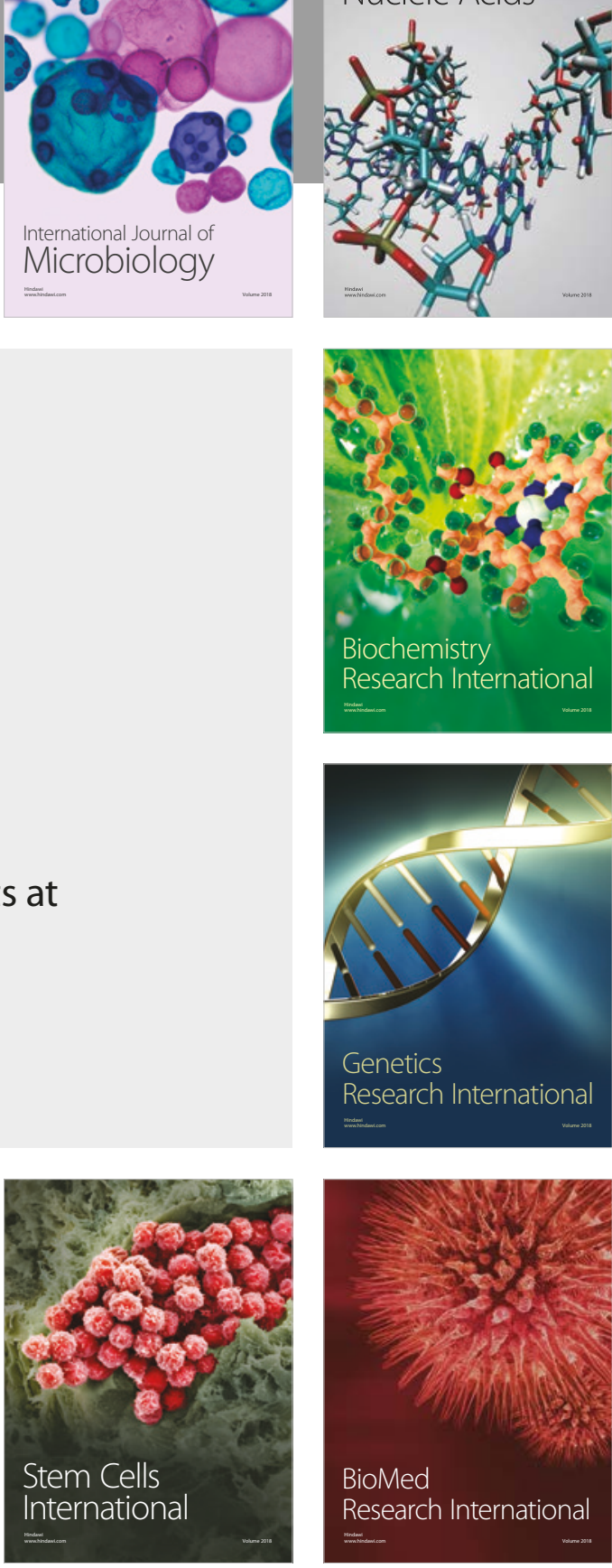
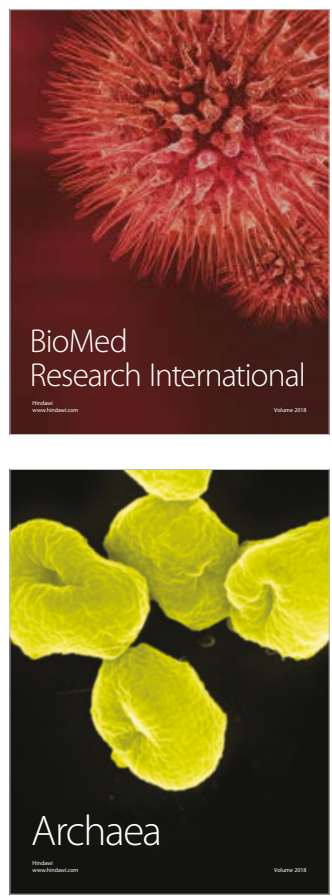